\title{
Conf- $7905-10-7$
}

\section{MASTER}

PREPRINT UCRL-82677

\section{Lawrence Livermore Laboratory}

MAGNETIC PROPULSION RAII.GUNS: THEIR DESIGN AND CAPABILITIES

R. S. Hawke and J. K. Scudder

May 8, 1979

This paper was prepared for the Second International Conference on Megagauss

Magnetic Field Generation and Related Topics, May 29 to June 1, 1979, Washington, D.C.

This is a preprint of a paper intended for publication in a journal or proceedings. Since changes may be made before publication, this preprint is made available with the understanding that it will not be cited or reproduced without the permission of the author.

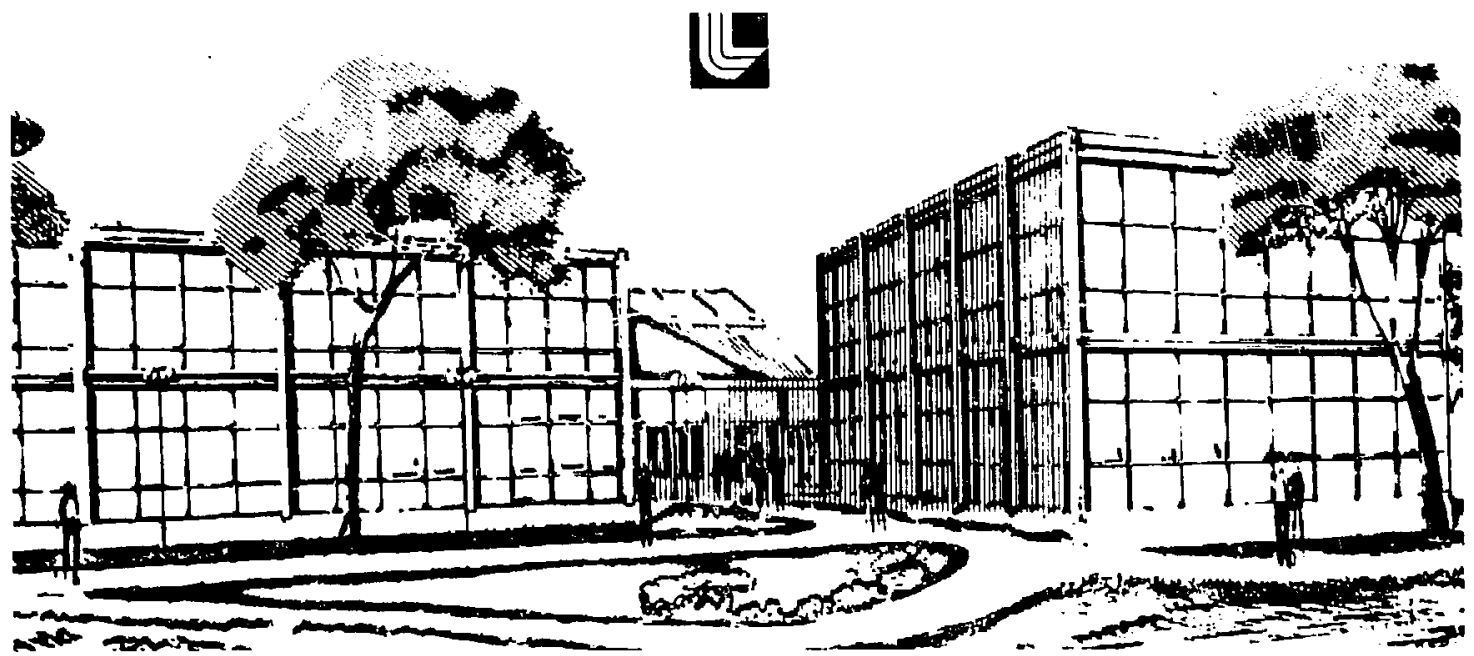

ito tonine- 
MAGNETIC PROPULSION RAILGUNS: THEIR DESIGN AND CAPABILITIES

R. S. HAWKE, J. K. SCUDDER

University of California

Lawrence Livermore Laboratory,

Livermore, California 94550

United States of America

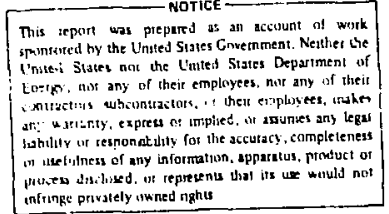

ABSTRACT

Recent research has revived interest in electromagnetic railguns. A railgun utilizes the Lorentz force to accelerate an electrically conducting armature, which in turn accelerates a projectile. Our investigation identified the critical parameter that will lead to limits on railgun operation. These limits were incorporated in calculations of the performance of railguns. The calculations indicate that it is possible with present technology to accelerate a projectile to velocities in excess of $20 \mathrm{~km} / \mathrm{s}$. 


\section{INTRODUCTION}

The long history of magnetic propulsion was recently highlighted by the successful work of Rashleigh and Marshall [1], and Barber [2] at Australian National University (ANU) as well as Kolm [3] at Massachusetts Institute of Technology. Their exciting experimental results with dc "railguns" [1,2] and synchronous ac "mass-drivers" [3] are in marked contrast to earlier results of others.

Although diverse approaches had been taken by previous researchers, results were remarkably similar. Generally speaking, the anticipated 10 to $30 \%$ electrical-to-mechanical conversion of energy was not realized. It was concluded from early results that a full-scale version of the envisioned propulsion system would be impractical because of the excessively large power source required. The latest results $[2,3]$, however, suggest that high efficiency is possible and that many propulsion applications are practical.

In this paper we examine the fundamental and technical issues believed to control dc-railgun efficiency and performance. Topics discussed include resistive heating and magnetic loading of the parallel rails; stress considerations within the rail support structure; interior ballistics of the projectile, including dynamic loading and drag; and, finally, estimates of launcher performance as a function of input energy.

Our results suggest possible reasons for both the successes and failures of prior experiments with macroparticle accelerators and, further, indicate a sequence of critical measurements that should be performed to test our design criteria. 


\section{PRINCIPLES OF RAILGUN OPERATION}

The magnetic railgun is essentially a linear dc motor consisting of a pair of rigid parallel conductors that carry current to and from a small interconnecting movable conductor. The connecting link functions as an armature while the parallel rails serve as a single-turn field winding (see Fig. 1). The force $F$ on the armature is given by,

$$
F=\frac{L_{I} I^{2}}{2},
$$

where I is the armature current, and $L_{1}$ is the inductance per unit length of the rail pair, and

$$
L_{1}=\frac{Z_{0}}{c}
$$

where $z_{0}$ is the characteristic impedance of the rails, and $c$ is the speed of light.

A typical "square bore" configuration, where the rail separation $w$ is equal to rail height $h$, has an $L_{1}$ equal to $0.42 \mu \mathrm{H} / \mathrm{m}$. Thus a $10^{6}-\mathrm{A}$ current will produce $2.1 \times 10^{5}$ Newtons of thrust on the armature. $A$ projectile consisting of a conducting armature and a nonconducting payload with a combined mass of $0.1 \mathrm{~kg}$ will experience an acceleration of $2.1 \times 10^{6} \mathrm{~m} / \mathrm{s}^{2}$, and after one meter of travel will achieve a velocity of $2 \mathrm{~km} / \mathrm{s}$.

It is not necessary that the armature be a solid conductor. Brast [4] and Marshal1 [5] demonstrated that an arc discharge initiated across the base of a dielectric projectile can also act as an armature if it is confined behind the projectile. The confinement is provided by the conducting rails on two sides and dielectric rail spacers on the other two sides. 
The components of a rail system are shown in Fig. 2. When switch $\mathrm{S}_{1}$ is closed, a primary energy-storage device (PESD): such as a capacitor bank or homopolar generator (HPG), generates a current in the storage indicator $L_{0}$, which functions as a pulse conditioner. When the desired, usually maximum, current is established in $L_{0}, S_{2}$ is closed to isolate the PESD from the railgun circuit. At this time, the shuttle switch $S_{3}$, a sliding multifingered conductor between two busbars, is moved across the breech of the railgun. As the shuttle traverses the breech, the fuse or solid armature allows current to continue to flow without arcing. The overloaded fuse rapidly vaporizes, however, and establishes the initial plasma arc, which accelerates the projectile along the rails. Just prior to the emergence of the arc or solid armature from the muzzle of the gun, a crowbar switch $S_{\Delta}$ is closed to extinguish the plasma arc and avoid spurious arcing elsewhere in the gun.

The specific applications and ultimate mass-velocity combinations that can be achieved with railguns will depend on a number of factors as discussed later.

\section{RAILGUN SIMULATION CODE}

The railgun simulation code combines equations of motion, Kirchhoff's law, and the conservation laws.

A. Equations of motion

The acceleration a is given by,

$$
a=\int_{0}^{w} \frac{\vec{I} \cdot d \vec{w} \times \vec{B}}{m}=\frac{L_{1} I^{2}}{2 m}
$$

where $B$ is the magnetic field intensity in the region of the armature, and $m$ is the mass of the armature and projectile. 


\section{B. Circuit analysis}

The resistive voltage drop through a solid armature is small [5] and, therefore, has a negligible effect on the circuit performance. At high current density, the plasma arc voltage $V_{A}$ is nearly constant and equal to about $200 \mathrm{~V}$.

The voltage $V_{I}$, resulting from the time variations of the current and inductance $L$ of the railgun is given by

$$
V_{I}=\frac{d(L I)}{d t}=L \frac{d I}{d t}+I \frac{d L}{d t} \text {, }
$$

and since,

$$
\begin{aligned}
& L=L_{1} z, \\
& \frac{d L}{d t}=L_{1} v .
\end{aligned}
$$

The voltage $V_{R}$ along the rails, is given by

$$
V_{R}=2 \int_{0}^{z} I R d z
$$

where $R$ is the resistance of each rail. Iterative calculations were used to determine the temperature, resistivity, current diffusion, and resistance of the rails as functions of current density and time and are described in Section 4-B. Using Kirchhoff's $1 \mathrm{aw}$, we obtain the relation,

$$
I R_{0}+L_{0} \frac{d I}{d t}+I R+I \frac{d L}{d t}+L \frac{d I}{d t}+V_{A}=0
$$

from which the current and voltages are calculated.

\section{Conservation of energy}

The following equations are used to calculate the distribution of energy throughout the projectile's acceleration. The instantaneous energy ${ }_{C}$ in the storage coil is simply, 


$$
E_{C}=\frac{L_{0} I^{2}}{2} .
$$

Similarly, the inductive energy, $E_{I}$, between the rails is,

$$
E_{I}=\frac{2 L_{1} I^{2}}{2} \text {. }
$$

The resistive energy loss, $E_{S}$, in the solid armature is

$$
E_{S}=\int I^{2} R_{S} d t \text {, }
$$

where $R_{S}$ is the resistance of the armature.

The energy loss, $E_{A}$, in the plasma arc armature is given by

$$
E_{A}=\int V_{A} I d t \text {. }
$$

The energy loss, $E_{R}$, in the fixed circuit elements and rails is

$$
E_{R}=\int I^{2} R_{0} d t+2 \int I^{2} R d t \text {. }
$$

And, finally, the kinetic energy, $E_{p}$, of the projectile is given by,

$$
E_{p}=\frac{m v^{2}}{2}
$$

\section{LIMITING FACTORS THAT INFLUENCE LAUNCHER DESIGN}

The design and operation of a railgun is restricted by practical limits. These limits result from the properties of the rail and projectile materials, interior ballistics of the projectile, sustainable voltage without spurious arcing, and available energy.

\section{A. Solid armature meiting}

Clearly, melting of the solid armature is a limiting factor. When the current penetration into the armature during the acceleration is less than the length $\ell^{\prime}$ and height $r_{i}$ of the conductor, the maximum velocity $v_{M}$ is approximated by 


$$
v_{M} \sim \frac{\rho^{\prime}\left(C_{0}^{\prime} \Delta T\right)^{2}}{2 \pi \mu_{0}^{\prime} n_{0}} \cdot \frac{h \ell^{\prime}\left(h+\ell^{\prime}\right)^{2}}{w} \cdot \frac{L_{1}}{I^{2}}=k \frac{h \ell^{\prime}\left(h+\ell^{\prime}\right)^{2}}{w} \cdot \frac{L_{1}}{I^{2}}
$$

where $\rho^{\prime}$ is the mass density, $C_{v}^{\prime}$ is the specific heat at constant volume, $\mu_{0}^{\prime}$ is the permeability, $\eta_{0}^{\prime}$ is the resistivity, and $\Delta T$ is the initial allowable temperature rise of the armature material.

The coefficient $K$ is $\sim 5.5\left(10^{27}\right)$ and $\boldsymbol{\alpha} 2.1\left(10^{27}\right)$ in SI units for copper and aluminum, respectively. For a cubical copper armature, where $h=w=\ell^{\prime}=10 \mathrm{~mm}, V_{M} \sim 9.2\left(10^{15}\right) / I^{2}$ in $(m / s) / A^{2}$. Hence for $I=10^{6}$ amps, $v_{M} \sim 9 \mathrm{~km} / \mathrm{s}$, which illustrates there is a velocity above which the plasma armature will be required.

\section{B. Rail melting}

Not only is melting of the rails undesirable, but high temperatures decrease their strength. More [6] calculated the temperature rise and resistance of the rails as follows.

The current density $j$ in the rails is given by

$$
j=\frac{\partial H}{\partial x},
$$

where $H$ is the magnetic field, and $x$ is the dimension normal to the rail surface. Because the dimensions of the rails are large compared to the current penetration depth, one-dimensional analysis is adequate.

The diffusion of $H$ into the conductor is given by

$$
\mu_{0} \frac{\partial H}{\partial t}=\frac{\partial}{\partial x}\left(n \frac{\partial H}{\partial x}\right) \text {, }
$$

and

$$
\rho C_{v} \frac{\partial T}{\partial t}=\frac{\partial}{\partial x}\left(k \frac{\partial T}{\partial x}\right)+n\left(\frac{\partial H}{\partial x}\right)^{2}
$$


where $\mu_{0}$ is the permitivity, $\eta$ is the resistivity, $C_{v}$ is the specific heat, $k$ is the thermal conductivity, and $\rho$ is the mass density of the rails.

The electrical resistivity is assumed to be described by

$$
\eta=n_{0}+\alpha T \text {, }
$$

where $n_{0}$ is the initial resistivity and $\alpha$ is the temperature coefficient.

Equations (16) through (19) are solved as implicit finite-difference equations [7], producing the temperature profile and resistance of the rails as functions of time, rail dimensions, and current. The calculated rail resistance was used in the simulation code described in Section 3. The maximum temperature rise occurs on the surface of the rails and is shown in Fig. 3, as a function of current per unit of rail perimeter $p=2(h+d)$ where $d$ is the rail thickness. Results are shown for two initial temperatures $T_{0}$ and are in close agreement with Kidder's approximation [8],

$$
\Delta T \sim \frac{2 \mu_{0} I^{2}}{\pi C_{v} p^{2}} \ln \left[1+\frac{\pi}{2} \sqrt{\frac{C_{v}{ }^{n} 0}{\mu_{0} k}}\right] .
$$

We conclude that for a copper rail system initially at room temperature, the perimeter current density may be 1 imited to $43 \mathrm{MA} / \mathrm{m}$. Here we only considered the effects of a single launch. Rapid repetitive launching would require heat removal during its operation.

\section{Launcher stress}

The railgun structure is subjected to a complex set of loads that result from intense pulsed magnetic fields, high temperature gradients, sliding-contact-induced shear, and mechanical deformation. It is valuable to have estimates of the stress states of each component, because in many 
cases each must function in a dual (or multiple) role. For example, while the primary function of the rails is to conduct the armature current, the rails must also guide and perhaps contain the projectile as well as provide a thermal conduction path for the surface-generated heat. Similarly, the dielectric region surrounding the rails provides not only electrical isolation but also mechanical support for the rails and guidance for the projectile. Thus, it is necessary to consider both the direc: and indirect influences of each perturbation.

As a representative problem, we consider the quasi-static behavior of a square-bore, parallel-rail accelerator in the geometry of Fig. 4a. This example shows the influence of the flow characteristics of the dielectric upon the peak stress in the rails and surrounding support tube. In these calculations, the applied stress was taken to be constant along the inner face of each rail and was increased until either the rails or the tube yielded $(980 \mathrm{MPa})$.

In the case of polymethylmethacrylate (PMMA) dielectric, the internal magnetic pressure was $150 \mathrm{MPa}$ at the time of yield. Figure $4 \mathrm{~b}$ shows that as a result of the low strength of PMMA pronounced bending of the rails occurs, which in turn raises the equivalent stress at the center of the inner rail surface to beyond the elastic limit.

Figure $4 c$ indicates the changes in stress state that occur when a rigid dielectric $\left(\mathrm{Al}_{2} \mathrm{O}_{3}\right.$, alumina ceramic) is substituted. Here, yielding does not occur until the internal magnetic pressure reaches $300 \mathrm{MPa}$. Plastic failure occurs in the tube while the stress in the rail is well below the elastic limit.

Note that the partially compensating support from the field between the back of the rail and the inner wall of the tube has been omitted. In 
fact, one can expect to significantly reduce the bending moment on the rails as well as the compressive load on the dielectric through proper field shaping in the rail-to-tube gap [9]. It must also be recognized that, in contrast to the assumptions made for these calculations, the magnetic stress on the rails will not necessarily be uniform.

\section{Projectile stress}

As with the rails and their support structures, the projectile will deform according to the waveshape, amplitude, and distribution of the applied stress, and the flow characteristics of the projectile material. If the acceleration forces on the projectile exceed its elastic strength $\sigma_{y}$, the excess load will result in a normal force on both the rails and the dielectric. A force of this kind has both beneficial and dissipative effects. First, if the current transfer from one rail to another is to be accomplished through the sliding contact, then the added contact force will support a greater armature current. The negative aspect, however, is the resulting frictional drag and associated wear and erosion of both projectile and barrel. This topic is discussed in Section 4-F.

An alternative apprnach is to limit the acceleration stresses to less than the elastic limit, the projectile material. In this case, the cross section of the projectile is undersized to provide growth room under acceleration. The seal to the bure that is required for arc propulsion could be accomplished with collapsible support rings attached to the projectile.

The maximum allowable acceleration $a_{M}$ is then set by the strength-to-density ratio of the projectile and its length. That is,

$$
a_{M}=\frac{\sigma y^{A}}{m}=\frac{\sigma y}{\rho l} .
$$


Setting $a_{M}$ equal to the projectile acceleration in terms of the rail current and projectile mass (Eq. 3), we have

$$
a_{M}=\frac{\sigma_{y}}{\rho_{\ell}}=\frac{L_{1} I^{2}}{2 M}
$$

and finally,

$$
\frac{\mathrm{I}_{M}}{[\mathrm{wh}]} \overline{1 / 2}=\left[\frac{2 \sigma_{y}}{\mathrm{~L}_{1}}\right]^{1 / 2},
$$

where $I_{M}$ is the maximum current that can be used to accelerate the projectile. For a square-bore projectile made from a composite of resin and graphite fibers with an elastic strength of $1.4 \mathrm{GPa}, I_{\text {MAX }} /[$ Wh] $1 / 2$ $=81 \mathrm{MA} / \mathrm{m}$. With this approach, accelerations of $10^{6}$ to $10^{7} \mathrm{~m} / \mathrm{s}^{2}$ may be achieved without excessive loading of the bore. E. Projectile stability

The considerations of rail heating and magnetic loading lead one to the conclusion that for a given projec:ile mass, the launcher cerformance will increase with increased bore size. The improvement shouid continue until the length-to-width or length-to-diameter ratio (i.e., aspect ratio) of the projectile is so small that the projectile can tumble or wedge in the bore. Barber discusses this problem from the standpoint of Taylor instabilities and thereby estimates a minimum ratio of 0.64 [2]. Experience with the $7 \mathrm{~km} / \mathrm{s}$, two-stage, light gas gun at Lawrence Livermore Laboratory has been that an aspect ratio as low as 0.5 is acceptable. F. Combined sliding, heating, and boundary-layer energy losses

Buckingham [10] has calculated the drag and heating losses caused by sliding friction, solid deterioration at the surface, and by the liquid and gaseous boundary layers between the projectile and the launcher walls. 
The worst case predicted is when the acceleration of the projectile exceeds the strength-to-density limit of Eq. (21). In this case, the accelerating pressure causes the projectile to be in rubbing contact with o the bore of the gun. The sliding friction will result in considerable drag and heating of the projectile. When the elastic strength of the projectile is zero, it is totally plastic and the amount of energy dissipated by drag will be of the order of 20 to $50 \%$ or more of the kinetic energy of the projectile, depending on the geometry of the projectile and the coefficient of sliding drag.

Whenever the acceieration is less than the limit of Eq. (21), the projectile can be self-supporting and not require the gun bore to constrain its shape. In this case, three possible types of projectile-gun bore interactions can occur: (1) mixed phase (liquid, solid particulate) suspension, gaseous or liquid metal (melt) boundary layer heating, (2) erosive mass transfer, and (3) solid body impact (in the absence of significant mass erosion or alignment bands).

If significant melting or erosion occurs as a result of boundary layer heating so that a substantial mixed-phase (gas, liquid, solid) mass residue builds up in the projectile-launcher gap, the side-wall solid-body impact is suppressed by the intervening layer. Calculation of the drag energy loss is based on erosive heat and mass transfer.

In Fig. 5, the calculated energy dissipated by drag is shown for liquid Fe and gaseous graphite and nitrogen boundary layers as a function of the clearance between a projectile (10 $\times 10 \times 5-\mathrm{mm}$ long $)$ and the gun bore. In these calculations, a force equivalent to a drag-free acceleration of $10^{8} \mathrm{~m} / \mathrm{s}^{2}$ was applied to the back side of the 
projectile for a distance of $200 \mathrm{~m}$, which would result in a muzzle velocity of $200 \mathrm{~km} / \mathrm{s}$.

A liquid iron boundary layer is equivalent to a zero-clearance. In this case, the additional energy needed to accelerate the projectile and the resultant heating is significant.

In the case of gaseous boundary layers, both laminar and fully developed turbulent forms were considered. It can be argued from both a thenretical and an experimental viewpoint that the fully developed turbulent boundary layer (an upper limit for boundary layer heating and mass transfer) is improbable. There are at least two reasons for this. First, the entire launch phase lasts only a few milliseconds even for a 200-m launcher. This is too short a period for transition and full development of the turbulent boundary iayer, particularly in the supersonic flows where destabilizing influences tend to be rapidly swept downstream. Furthermore, experimental evidence indicates that turbulence is supressed to the extent that laminar boundary layers may reform even at much more modest acceleration levels than that of the railgun launch. 10 However, the drag predictions are based for the most part on fully developed, turbulent boundary layer assumptions to insure that they are conservative estimates. Even so, up to 100 to $200 \mathrm{~km} / \mathrm{s}$ the boundary-layer drag losses predicted are insignificant in comparison to the propulsive energy supplied. This points out an important aspect of future railgun research; namely, to provida experimental verification of the internal ballistics drag and erosion phenomena at hypervelocity (super orbital) speeds and several millions of g's acceleration. 
G. Arcing between rails

If the railgun is to operate effectively, it is important that the moving arc or metal armature be the only conduction path across the rails. Hence, conditions that could develop secondary arcs must be avoided.

The largest voltage developed across the rails occurs at the breech and is the sum of the arc, inductive, and resistive voltages along the rails. The breakdown voltage is a function of rail spacing and gas pressure. The minimum breakdown voltage resulting from Paschen's law must be avoided. For low velocity applications, either high or low gas pressure would suffice. For high velocity applications, the pressure should be below $10^{-4}$ Torr during acceleration, thereby avoiding axcessive drag and possible collisional ionization of gas in front of the projectile. After the acceleration is completed, however, it is possible to launch the projectile into a normal atmospheric environment. H. Available energy

In addition to all the above considerations, the performance of a railgun launcher is determined by the amount of energy delivered to it. The maximum delivered energy is equal to the energy stored in the PESD less the energy loss in transfer from the PESD to the storage inductor and then to the railgun.

\section{PERFORMANCE CALCULATIONS}

\section{A. Velocity vs. mass vs. energy}

In the calculations described in Section 3, we used the practical limits described in Section 4 to estimate the performance of railguns. To focus attention on the railgun operation, we based the calculations on the 
amount of energy $E_{0}$ initially stored in the inductor at the commencement of projectile acceleration rather than on the energy stored in the PESD.

Figure 6 shows the calculated velocity vs. initial energy for 5-, 10-, 50-, and 200-g projectiles as they exit from 5-, 10-, 20-, and 40-m-long accelerators. For $E_{0}$ less than $3 \mathrm{MJ}$, all of the energy is distributed within $5 \mathrm{~m}$ of acceleration. At higher energies, longer accelerators are needed to utilize the available energy. The dashed lines indicate the maximum velocities attained with the imposed limits. The circled numbers indicate the efficiency of conversion from stored electrical to kinetic energy.

Figure 7 shows the predicted velocity as a function of the mass of the projectile, starting with 1, 10, and $100 \mathrm{MJ}$ of energy in the storage inductor. A wide range of mass and velocity combinations can be attained with a single energy-storage system. The operational projectile mass and maximum velocity combinations of the LLL two-stage gas gun are indicated for reference.

\section{B. Multiple section accelerator}

The above discussion has been limited to a single pair of rails, i.e., a single section railgun. Approximately $50 \%$ of the energy stored in the inductor is lost in resistive heating of the rails. Dividing the accelerator into several shorter, modular sections would (1) reduce the amount of energy loss in heating the rails, (2) allow the current to be re-established at the highest usable value in each section, (3) reduce the resistive voltage drop, and (4) provide a convenient division of the total amount of required energy into smaller units.

The total energy loss in the rails is proportional to $1 / \sqrt{\mathrm{N}}$ (see Ref. 11) where $N$ is the number of modules. 
The combined effect of the energy savings and the operation at near maximum current throughout the acceleration is illustrated in Fig. 8 , which shows the energy initially required in the storage inductor vs. velocity for 1-, 10-, and 100-section accelerators. A 100-section accelerator requires little more energy than an ideal accelerator where the required energy equals the sum of the kinetic energy of the projectile $E_{p}$ and the stored inductive energy $E_{I}$ between the rails. Hence, the multiple-section accelerator can approach the ideal case. Furthermore, part of the stored inductive energy could be recovered and lead to efficiencies in excess of $50 \%$.

\section{APPLICATIONS}

The spectrum of applications of an accelerator capable of delivering intact projectiles at velocities greater than $10 \mathrm{~km} / \mathrm{s}$ is very wide. A few representative cases are shown in Fig. 9. Research and technical development may lead to low-cost orbital launching. Equation-of-state research will advance immediately as the payload is delivered at velocities greater than those attained with two-stage gas guns ( 7 to $10 \mathrm{~km} / \mathrm{s}$ ) and high-explosive techniques $(6$ to $7 \mathrm{~km} / \mathrm{s})$. Impact pressures of 1 to $10 \mathrm{TPa}$ in medium- and high- 2 materials will be possible with velocities in the range of 7 to $35 \mathrm{~km} / \mathrm{s}$ [12]. Magnetic-field generation to presently unattained intensities will require velocities greater than $20 \mathrm{~km} / \mathrm{s}$ [13]. However, hybrid compression techniques such as magnetic compression followed by impact compression will be especially useful for compressing low- $Z$ materials. At very high velocities (>200 $\mathrm{km} / \mathrm{s}$ ) high-energy density research will be possible. 


\section{CONCLUSIONS}

We conclude that melting of metal armatures and rails, stress limits on launcher and projectile, spurious arciig, and amount of available energy result in fundamental limitations on railgun operation. We also find that adverse effects resulting from projectile instability and drag can be minimized. Certitude of our predictions suffers from the lack of experimental data in the regions of high-current density and dynamic loading. We, therefore, see excellent opportunities for applied research in magnetic propulsion and in pulsed-power technology. 


\section{ACKNOWLEDGEMENTS}

This work was performed under the auspices of the U.S. Department of Energy by Lawrence Livermore Laboratory under contract No. W-7405-Eng-48. The authors are eager to express thanks to those persons who are participating in the railgun development project. Specifically, we acknowledge the program support and guidance of John W. Kury and his staff as well as invaluable technical assistance from Jim Brittingham, Alfred Buckingham, Bruce Carder, Fred Deadrick, Gary Devine, Bill Gagnon, Neil Gibson, Don Meeker, Richard More, Bill Nellis, Steve Sackett, Harry Sahlin, Jim Shearer, Carl Wallace, Susan Weaver, and Roger Werne. Finally, we sincerely appreciate the help and patience of Sus an Boichat in preparing the manuscript. 


\section{REFERENCES}

[1] RASHLE IGH, S. C., MARShall, R. A., J. Appl. Phys. 49 (1978) 2540.

[2] BARBER, J. P., The Acceleration of Macroparticles and a Hypervelocity Electromagnetic Accelerator, B. Sc. Thesis, Australian National University, Canberra, Australia (1972).

[3] KOLM, H. H., Basic Coaxial Mass Driver Reference Design, in Proc. 3rd Princeton/AIAA Conference on Space Manufacturing Facilities (May 1977).

[4] BRAST, D. E., SAWLE, D. R., Study of a Rail-type MHD Hypervelocity Projectile Accelerator, in Proc. 7th Hypervelocity Impact Symposium, Vol. 1 (1964) 187.

[5] MARSHALL, R. A., The "Flying Fuse" in ANU Rail Gun, presented at 27 th Meeting of the Aeroballistic Range Association at Commissariat a l'Energie Atomique, Paris (1976).

[6] MORE, R., Lawrence Livermore Laboratory private communication, (1979).

[ 7] RICHTMYER, R. D., MORTON, K.W., Difference Method for Initial-Value Problems, Interscience Publishers, New York (1967).

[8] KIDDER, R. E., Nonlinear Diffusion of Strong Magnetic Fields into a Conducting Half-Space, UCRL-5467, Lawrence Livermore Laboratory, Livermore, California (1959). See also: H. Knoepfel, Pulsed High Magnetic Fields, North Holland Publ. Co., Amsterdam (1970) p. 80.

[9] SCUDDER, J. K., HAWKE, R. S., Field Shaping for the Direct-Current Railgun, to be published.

[10] BUCKINGHAM, A. C., Railgun Accelerator Projectile Drag Estimates During Launch, to be published. 
[11] BRITTINGHAM, J. N., HAWKE, R. S., Magnetic Gradient and Railgun Accelerators for Launching $0.1-g$ Payloads at Velocities Greater Than $150 \mathrm{~km} / \mathrm{s}$, UCRL-52778, Lawrence Livermore Laboratory, Livermore, California (1979).

[12] HAWKE, R. S., SCUDDER, 3. K., Prospects for Generating 1 to $10 \mathrm{TPa}$ Pressures with a Railgun, to be published in Proc, 7th AIRAPT International High Pressure Conference, July 30 to August 3, 1979, Le Creusot, France.

[13] FOWLER, C. M., CAIRD, R. S., HAWKE, R. S., BURGESS, T. J., in High Pressure Science and Technology, Vol. 2, K. D. Timmerhaus and M. S. Barber, Eds. (Proc. of 6th AIRAPT International Conference, Boulder, Colorado, 1977), p. 981.

NOTICE

"This report was prepared as an account of work sponsored by the United States Government. Neither the United States nor the United States Department of Energy, nor any of their employees. nor any of their contractors, subcontractors, or their employees, makes any warranty, express of implied, or assumes any legal liability or responsibility for the accuracy, completeness or usefulness of any information, apparatus, product or process disclosed, or represents that its use would not infringe privately-owned rights." 
FIGURES

Fig. 1. Railgun accelerator.

Fig. 2. Components of a railgun system: I, current source (HPG or capacitor bank); $L_{0}$, storage inductor; $R_{0}$, circuit resistance; $F$, fuse or solid armature; $P$, projectile; $S_{I}$, coil-charging switch; $\mathrm{S}_{2}$, source crowbar; $\mathrm{S}_{3}$, shuttle switch; and $\mathrm{S}_{4}$, armature crowbar.

Fig. 3. Rail surface temperalure rise as a function of ratio of current to rail perimeter, I/P.

Fig. 4. Calculated railgun-barrel-component deformation from magnetic stress on rails (deformations are magnified $2 x$ ). The equivalent-stress contour levels (MPa) - Part (b): $A=208, B=404$, $C=600, D=796, E=992 ;$ and $\operatorname{Part}(c): A=202, B=388, C=575$, $D=762, E=949$.

Fig. 5. Orag energy lost shown as a function of projectile-bore clearance.

Fig. 6. Muzzle velocity as a function of initial energy in storage inductor with 1.5 MA initial current. The percent figures indicate the efficiency of conversion from stored electrical energy to kinetic energy. The accelerator lengths are denoted as follows: 40m (0), $20 \mathrm{~m}(), 10 \mathrm{~m}()$, and $5 \mathrm{~m}()$. Curve Set $A$ is for a $5-\mathrm{g}$ projectile and $20-\mathrm{mm}$ rail perimeter; Set $B$ for a 50-g projectile and 30-mm rail perimeter; and Set $\mathrm{C}$ for a $200-\mathrm{g}$ projectile and $30-\mathrm{mm}$ rail perimeter.

Fig. 7. Attainable velocity versus projectile mass with 1,10 , and $100 \mathrm{MJ}$ of energy initially in the storage inductor (initial current 1.5 MA, rail perimeter $30 \mathrm{~mm}$, circuit resistance $10 \times$ storage inductance). 
Hawke

Fig. 3. Required energy in storage inductor versus projectile velocity for 1-, 10-, and 100-section railguns (projectile mass $1.23 \mathrm{~g}$, initial current of each section 0.75 MA, rail perimeter $40 \mathrm{~mm}$, circuit resistance $10 \times$ storage inductance).

Fig. 9. Spectrum of applications versus velocity for railgun accelerator. 


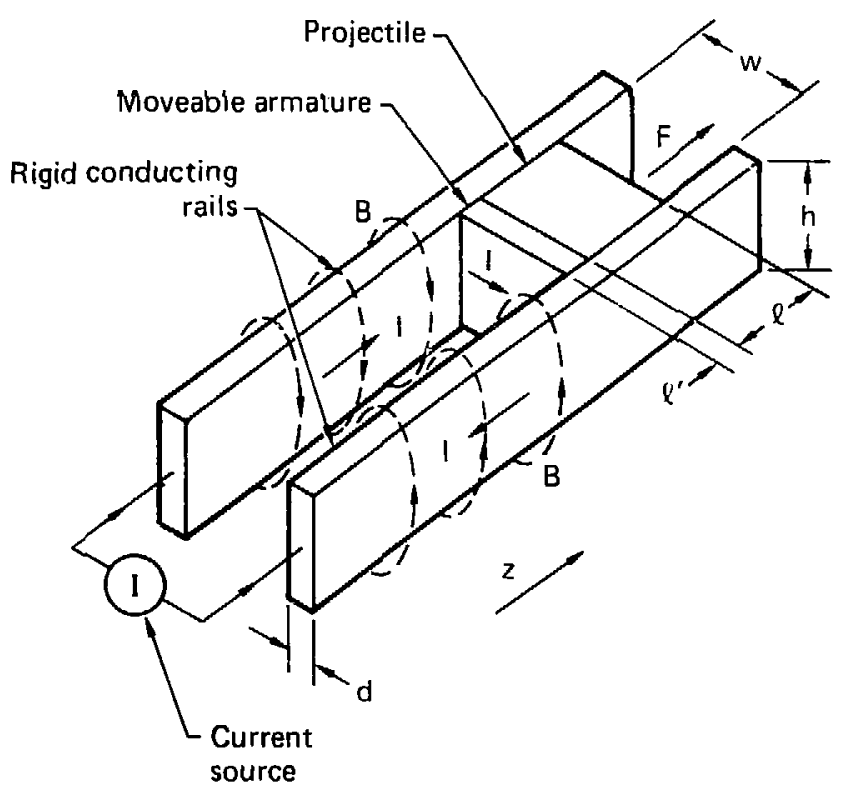

Hawke - Fig. I 


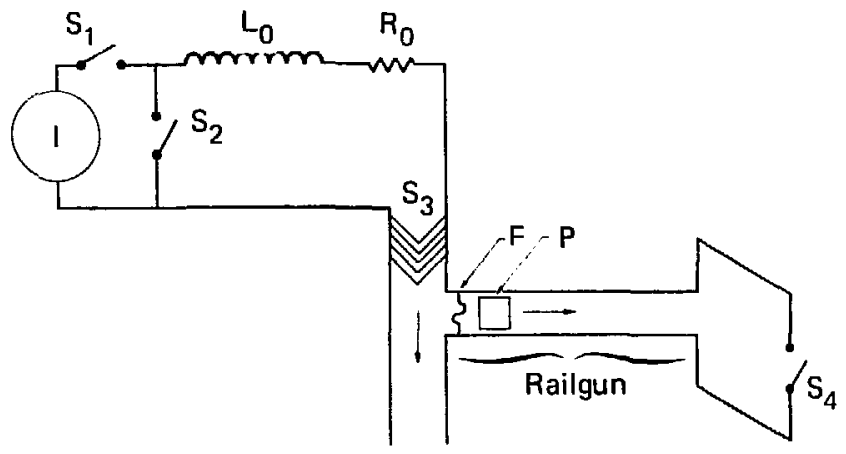

Hawke - Fig. 2 


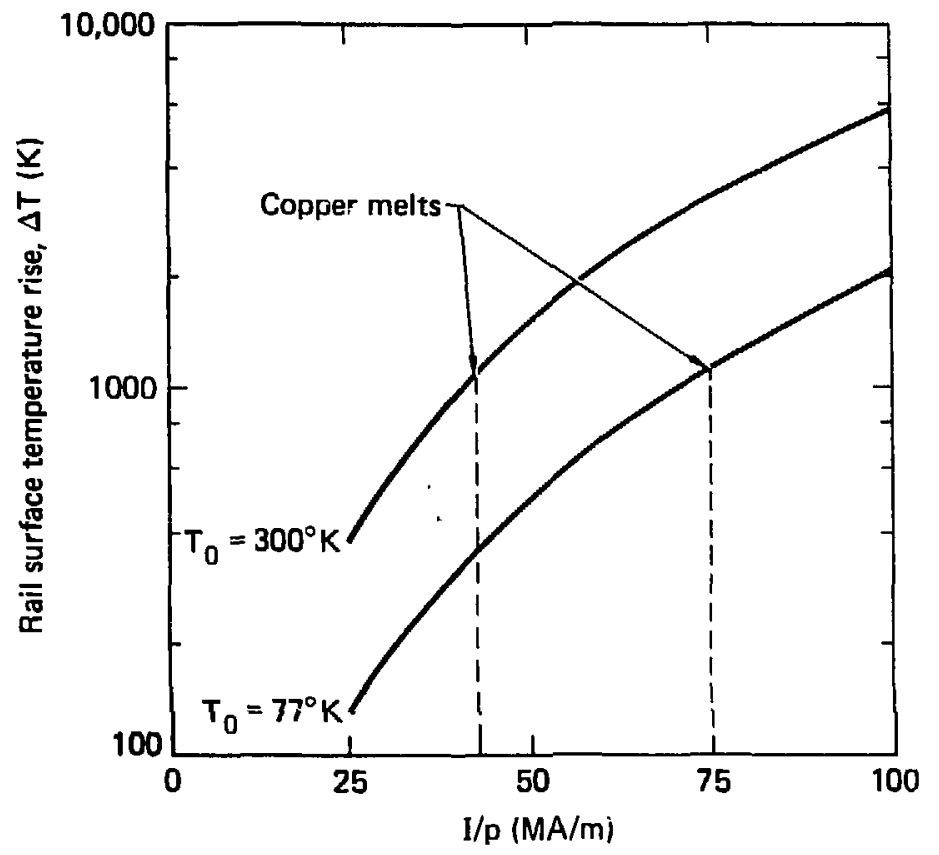

Hawke - Fig. 3 

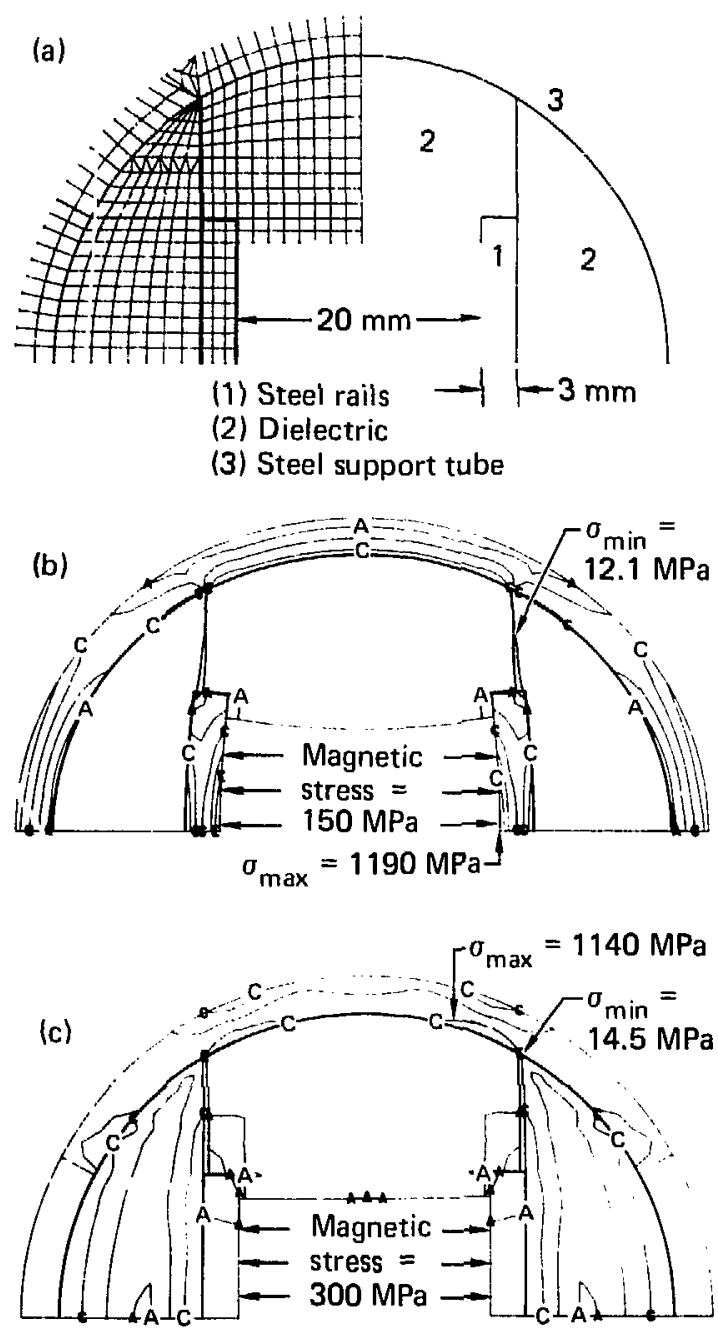

Hawke - Fig. 4 


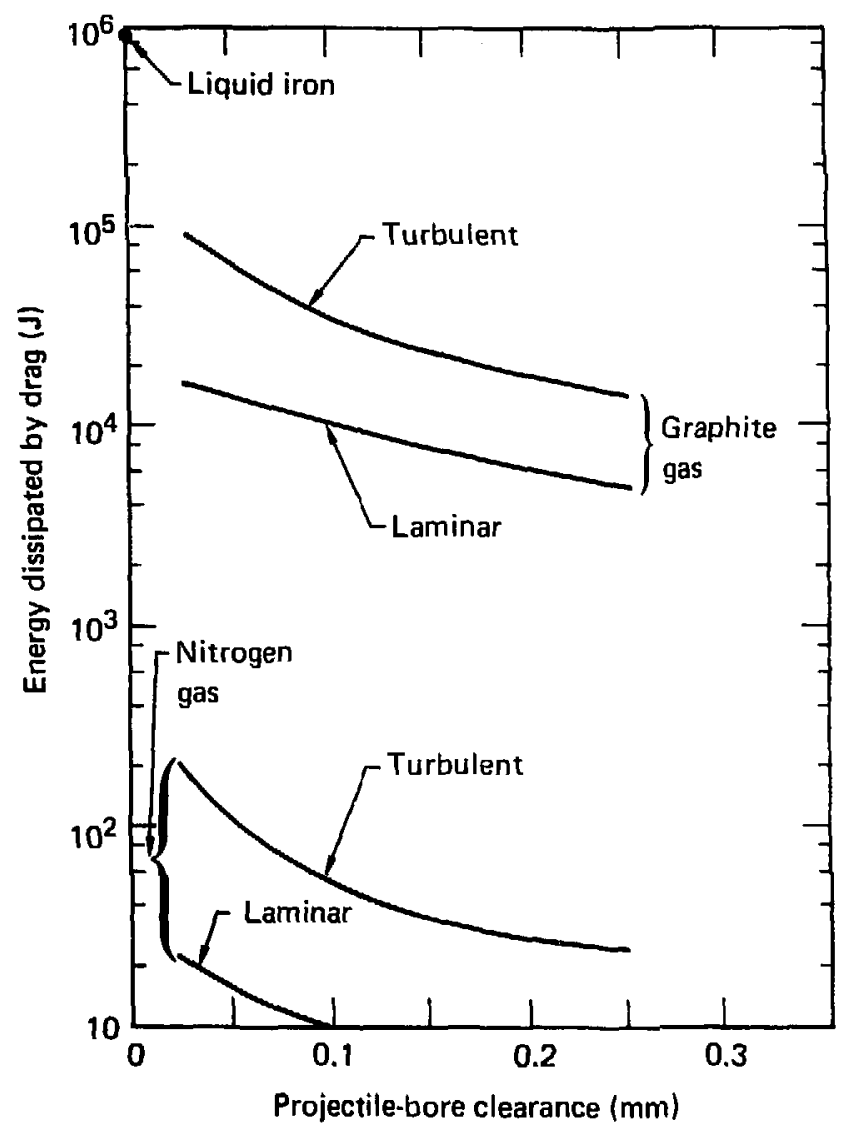

Hawke - Fig. 5

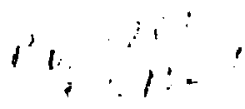




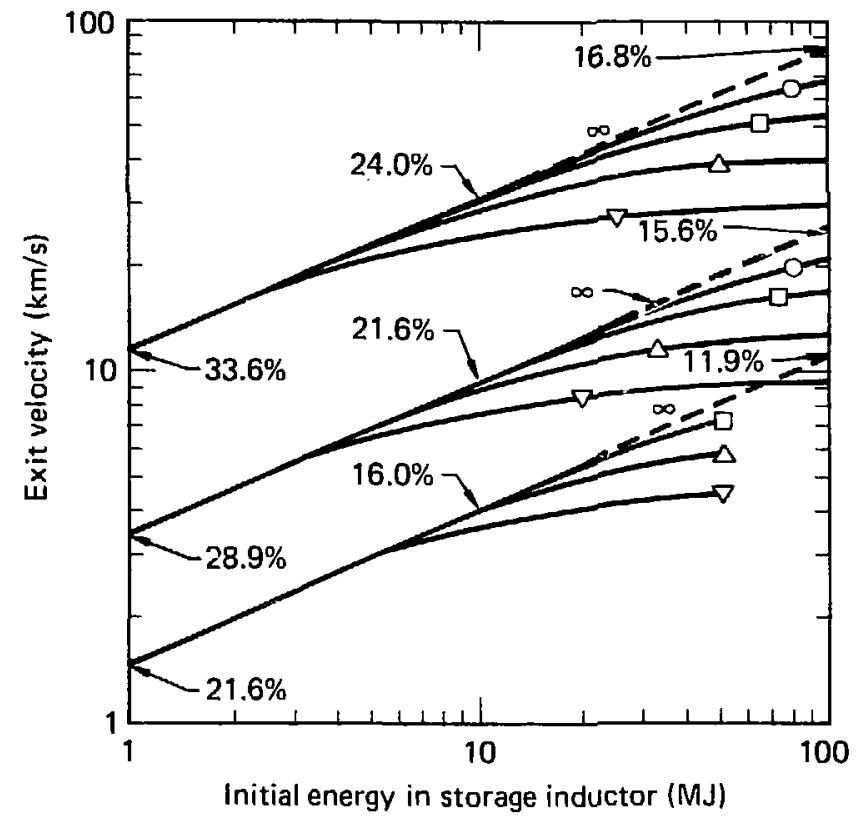

Hawke - Fig. 6

likn $42: \because$

Ai: $\% / 3$ 


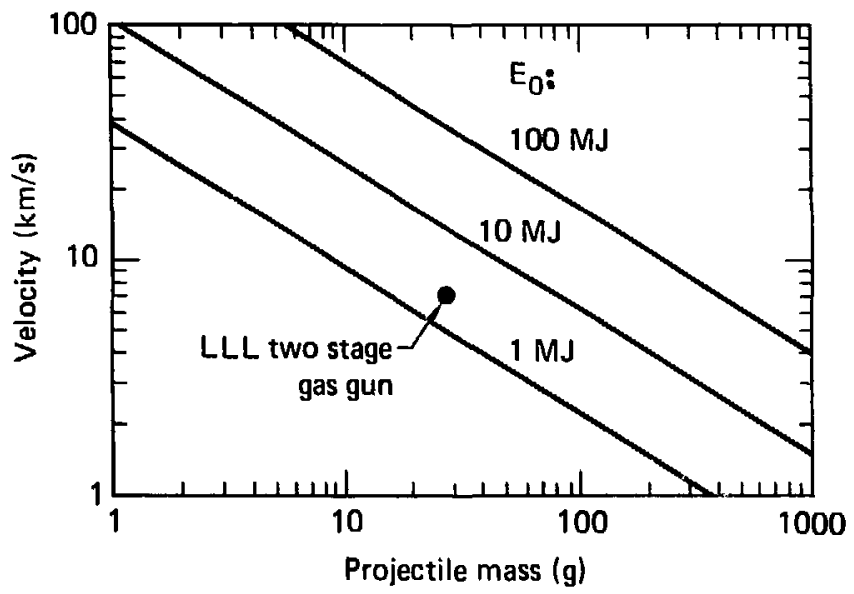

Hawke - Fig. 7 , ll 


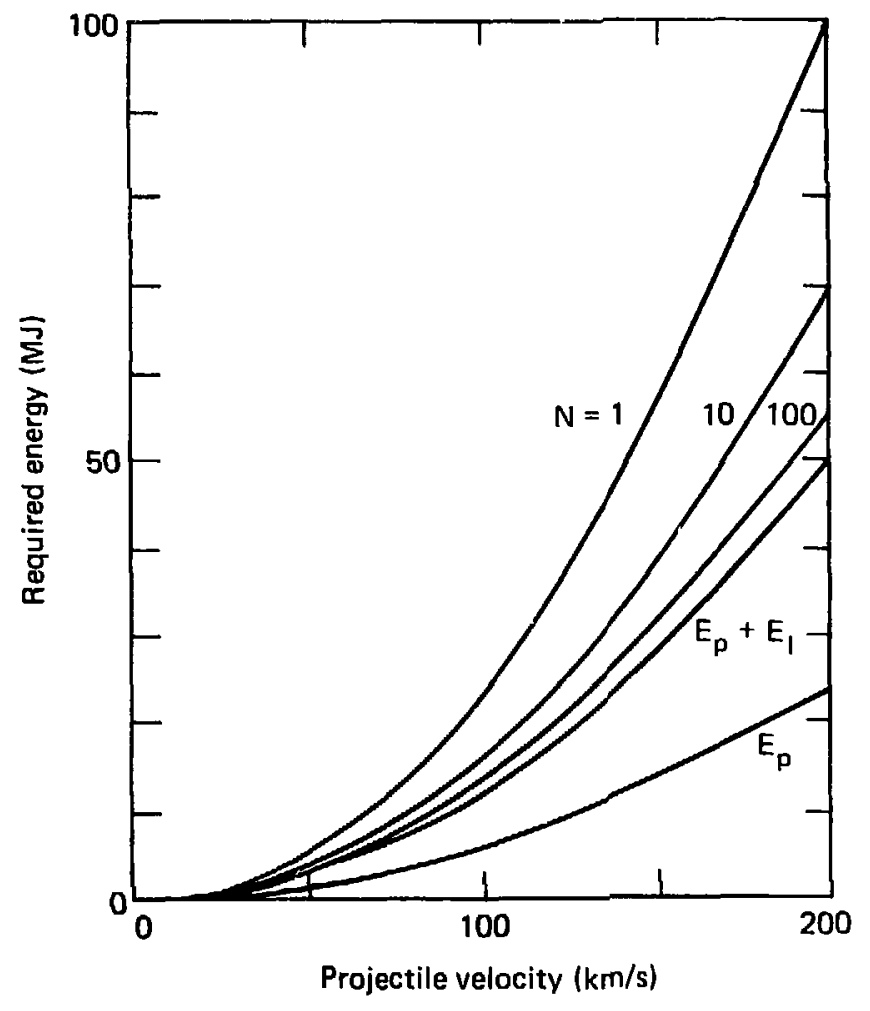

Hawke - Fig. 8

$\because . / 2 \%$ 


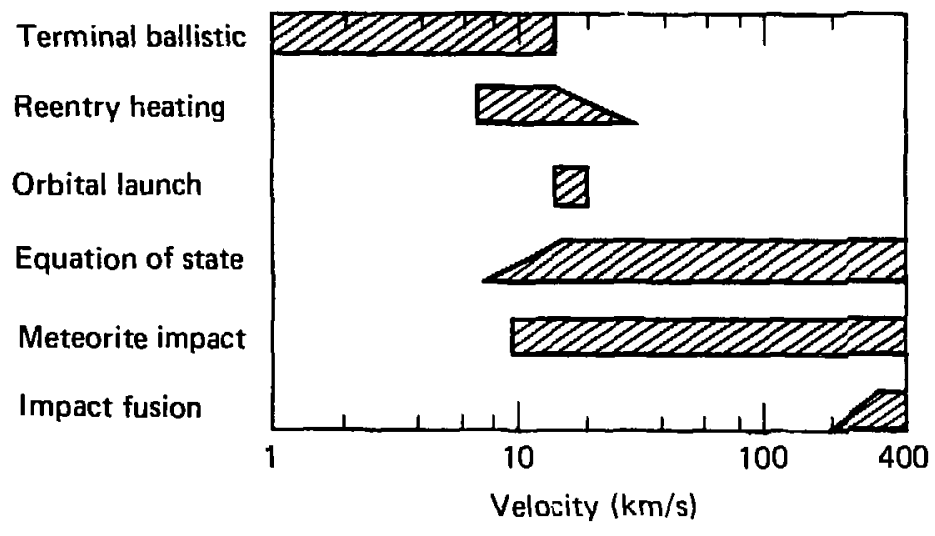

Hawke - Fig. 9 